\title{
RISK FACTORS OF NON COMMUNICABLE DISEASES (NCD) AMONG RURAL POPULATION OF PATANCHERU
}

\author{
B. Nirmala Devi1, M. Vijay Kumar ${ }^{2}$
}

\section{HOW TO CITE THIS ARTICLE:}

B. Nirmala Devi, M. Vijay Kumar. "Risk Factors of Non Communicable Diseases (NCD) among Rural Population of Patancheru". Journal of Evolution of Medical and Dental Sciences 2015; Vol. 4, Issue 14, February 16;

Page: 2335-2339, DOI: 10.14260/jemds/2015/337

ABSTRACT: BACKGROUND: Currently developing countries, especially India, are in a transitional phase, an epidemiological transition from a phase of predominantly infectious disease burden to a phase of triple burden of infectious diseases, chronic non-communicable diseases, and injuries largely due to demographic, lifestyle, nutritional and environmental changes. OBJECTIVES: To identify the burden of of Non-Communicable Diseases (NCDs) in rural population of Patancheru and to assess various risk factors of NCDs. MATERIAL \& METHODS: Present study was a part of American Association of Physicians of Indian Origin (APPIO) project. Total study population under the APPIO project was 1 lakh and target population of 20,000.It was a community based cross sectional study done in rural field practice area of Osmania Medical College, Patancheru. $1 / 4^{\text {th }}$ part of the project was completed and hence total sample size came to around 5000. Study population was all adults above the age of 20 years. Duration of study was 6 months from June to November 2013. Statistical analysis was done using EPI INFO version 7. RESULTS: Mean age of the respondents was 38.64 years, 52\% were males and $85.3 \%$ were married. Regarding risk factors for NCDs, tobacco usage in any form was present in $15.4 \%$, and alcohol consumption in $27.7 \%$ of the study population. High salt intake was seen in $17.8 \%$ and no regular intake of fruits \& vegetables in $17.8 \%$. Family history of Hypertension and Diabetes Mellitus was seen in 16.6\% \& 6.6\% respectively. Prevalence of Hypertension was 10\% and Diabetes was 4\%. About 5.1\% had Cardio vascular diseases (CVDs). CONCLUSIONS: Risk factors for NCDs were very much prevalent in the study population requiring appropriate \& timely actions to stop the emergence of epidemic of NCDs.

KEYWORDS: Non Communicable Diseases, Risk factors, Patancheru.

INTRODUCTION: Currently developing countries, especially India, are in a transitional phase, an epidemiological transition from a phase of predominantly infectious disease burden to a phase of triple burden of infectious diseases, chronic non-communicable diseases, and injuries largely due to demographic, lifestyle, nutritional and environmental changes.[1]Such phenomenon is not only seen in urban population but also evident in rural population.

According to World Health Organization (WHO) 2014 estimates on Non Communicable diseases (NCDs) in India, NCDs are estimated to account for $60 \%$ proportional mortality (\% of total deaths, all ages, both sexes) which include CVDs (26\%), cancers (7\%), chronic respiratory diseases (13\%), Diabetes (2\%), injuries (12\%) and other NCDs (12\%).Total deaths due to NCDs were 98, 16, $000 .{ }^{[2]}$

Majority of the NCDs share common risk factors such as tobacco use, high alcohol consumption, overweight \& obesity, inadequate physical activity and inappropriate dietary practices. Combination of the risk factors increases the morbidity and mortality of NCDs. ${ }^{[3]}$ These factors are interrelated to each other, so much so that appearance or occurrence of one factor leads for the other risk factor, thereby leading to the development of NCDs. 


\section{ORIGINAL ARTICLE}

\section{OBJECTIVES:}

1. To identify the burden of Non-Communicable Diseases (NCDs) in rural population of Patancheru.

2. To assess various risk factors of NCDs.

\section{MATERIAL \& METHODS:}

Study Design: Community based cross sectional study.

Study Setting: Patancheru which is the rural field practice area of Osmania Medical College was selected for the American Association of Physicians of Indian Origin (APPIO) project. Under the Rural Health Centre (RHC), there are 3 sub-centres which are Ghanpur, Chitkul and Ismailkhanpeta.

\section{STUDY SUBJECTS:}

Inclusion Criteria: Persons aged $\geq 20$ years, those who have given consent and willing to participant in study.

Exclusion Criteria: Persons suffering with severe debilitating conditions and those who were not present on the day of study.

Sampling Technique: To determine the burden of NCDs in India, APPIO project was undertaken. 2 states in the country were selected. One is Bihar and other one was Andhra Pradesh. From Andhra Pradesh, Osmania Medical College was selected and its Rural Health Centre area was selected as the study area. Total study population was 1 lakh and target population was 20, 000.

Sample Size: It was a part of the project and $1 / 4^{\text {th }}$ of the target population was selected as sample size which came to 5,000 .

Data Collection: From the 3 sub-centres, present study was done in Chitkul sub-centre and its corresponding villages. From the villages, cross sectional survey was done covering all the households by house to house visit. Persons who were above the age of 20 years and willing to participate were included in the study after obtaining the informed consent. A semi-structured questionnaire adapted from WHO STEP wise approach to Surveillance (STEPS) method was used for studying the risk factor profile.[4.5] The questionnaire contained three parts:

- In first part, regarding socio demographic and risk factors were assessed.

- In second part physical measurements, such as height, weight and waist circumference.

- In third Blood Pressure (BP) measurement.

Weight was recorded up to nearest $0.5 \mathrm{~kg}$. BMI (Body Mass Index) and WHR (Waist Hip Ratio) were calculated using these parameters.[6] Hypertensives were categorized as per the classification of seventh Joint National committee on Prevention, Detection, Evaluation and treatment of High Blood pressure.[7]

Study Duration: 6 months from June 2013 to November 2013.

Statistical Analysis: Data analysis was done using SPSS version 17 and STATA. Data was presented in percentages and proportions. Chi-square was applied to find out any significant associations with $\mathrm{P}$ value $<0.05$ considered as significant. 


\section{ORIGINAL ARTICLE}

RESULTS: Demographic characteristics revealed that the mean age of the study population was 38.64 years (Standard Deviation SD=14.641). Out of the 5000 participants, $52 \%$ were men. Majority $(85.3 \%)$ were currently married and about one-thirds of the study participants were illiterate.

\begin{tabular}{|c|c|c|}
\hline Risk factors & Number & Percentage \\
\hline Tobacco Use & 770 & $15.4 \%$ \\
\hline Alcohol consumption & 1385 & $27.7 \%$ \\
\hline Over weight and Obesity & 955 & $19.1 \%$ \\
\hline Sedentary habits & 2720 & $54.4 \%$ \\
\hline Irregular intake of fruits \& vegetables & 3480 & $69.6 \%$ \\
\hline High Salt Intake & 890 & $17.8 \%$ \\
\hline
\end{tabular}

Risk factors for NCDs were assessed. Tobacco usage in any form was present in $15.4 \%$. Smokes less tobacco use was higher among males as compared to females. Among males, (10.3\%) and among females (1.2\%) were current smokers. Mean age at which tobacco use started was 23.5 years (SD 5.3). Alcohol consumption seen in 27.7\% $(\mathrm{n}=1385)$ which was more among males compared to females. Obesity is an important factor for many NCDs specifically hypertension, dyslipidemias, diabetes mellitus and many other. Sedentary habits were seen in $54.4 \%$, irregular intake of fruits \& vegetables in $69.6 \%$ and high salt intake in $17.8 \%$ of the study population.

The prevalence of overweight and obesity (BMI - $>25 \mathrm{~kg} / \mathrm{m}^{2}$ ) was found to be $19.1 \%$. Mean BMI was $22.3 \mathrm{~kg} / \mathrm{m}^{2}$ and $23.5 \mathrm{~kg} / \mathrm{m}^{2}$ for males and females respectively. $24.5 \%$ of the study population were in the moderate to high risk category as per the Waist Hip Ratio (WHR) (Male $>0.96$, female $->0.80$ ).

\begin{tabular}{|c|c|c|}
\hline Family History & Number & Percentage \\
\hline Hypertension & 830 & $16.6 \%$ \\
\hline Diabetes Mellitus & 330 & $6.6 \%$ \\
\hline Heart Disease & 180 & $3.6 \%$ \\
\hline Heart Attack before age of 55 in Men and 65 in women & 505 & $10.1 \%$ \\
\hline Table No 2: Family History of NCDs \\
\hline
\end{tabular}

Regarding family history of NCDs, about $16.6 \%$ had family history of Hypertension, $6.6 \%$ with family history of Diabetes Mellitus, 3.6\% had a family history of Heart disease and family history of Heart Attack before age of 55 in Men and 65 in women was seen in 10.1\% of respondents.

\section{NCDS PROFILE:}

Hypertension: Overall prevalence of Hypertension among the study population was $10 \%(\mathrm{n}=500)$. Among the hypertensives, about $81 \%$ were currently on medication and $19 \%$ were not under any medication. 


\section{ORIGINAL ARTICLE}

Diabetes Mellitus: Prevalence of Diabetes was 4\% (n=200).

Cardiovascular Diseases (CVDs): Overall prevalence of Cardio vascular diseases was 5.1\% ( $\mathrm{n}=255)$. History of Heart Attack was present in 2.9\%.

Stroke: Stroke was seen in $2.3 \%(n=115)$ of the study population.

DISCUSSION: The risk factors of today are the diseases of tomorrow. Identifying these risk factors has a crucial role in public health as it helps to reduce the time lag between exposure and disease. This study with the aim of identifying these risk factors describes the prevalence of risk factors of NCDs among adults in a rural area of Patancheru. Study found a high prevalence of risk factors for NCDs. Tobacco use in any form was seen in $15.4 \%$ alcohol consumption in $27.7 \%$, over weight and obesity in $19.1 \%$. Sedentary habits were seen in $54.4 \%$, irregular intake of fruits \& vegetables in $69.6 \%$, high salt intake in 17.8\%, 16.6\% had family history of Hypertension, $6.6 \%$ with family history of Diabetes Mellitus

A similar study done by Saxena et al (2011) ${ }^{[8]}$ on 'Prevalence of risk-factors of noncommunicable diseases in rural population' in Dehradun observed that tobacco use was seen in $8.5 \%$, alcohol usage in $31.8 \%$, over weight and obesity in $14.8 \%$.

Another study done by Sochaliya KM et al (2012) ${ }^{[9]}$ in Jamnagar found that smoking was seen in $38 \%$, alcohol intake in $2 \%$, sedentary habits in $42.22 \%$, positive family history of Hypertension \& Diabetes in $69.33 \%$, high salt intake in $96.67 \%$, irregular intake of fruits \& vegetables in $25.33 \&$ 17.33 respectively. Study by Acharyya $\mathrm{T}$ et al (2010) ${ }^{[10]}$ in West Bengal found that smokeless tobacco was seen in $37.4 \%$, alcohol consumers in $15 \%$, irregular consumption of fruits in $22 \%$, over weight and obesity in $46.9 \%$.

NCDs Profile: In the present study, overall prevalence of Hypertension was $10 \%$ and Diabetes Mellitus was 4\%. Overall prevalence of Cardio vascular diseases was $5.1 \%$ and Stroke was seen in $2.3 \%$.

Sochaliya KM et al (2012) ${ }^{[9]}$ study observed that prevalence of Hypertension and Diabetes was $33.56 \%$ and $10.44 \%$ respectively.

Saxena et al (2011) ${ }^{[8]}$ found that prevalence of Hypertension as 6.6\%, Diabetes in $3.7 \%$ in the study population. Study by Acharyya T et al (2010) ${ }^{[10]}$ in West Bengal found that overall prevalence of Hypertension was $34.2 \%$.

Limitations of the study were that apart from hypertension, self-reported chronic conditions for Diabetes mellitus, CVDs and stroke was used in the study which may lead to an under estimation of these conditions. Cancers, Blindness could not be studied and only part of the project sample is given.

Though there is an existing health programme on NCDs in India, there is urgent need for health promotion programs with a special focus on reducing tobacco \& alcohol consumption, promotion of healthy dietary practices and physical activity at the basic primary health care level. Present study recommends creation of awareness for adopting healthy lifestyles for the prevention of NCDs. There is need for introducing lifestyle modification strategies especially targeting the risk population in the rural areas. 


\section{ORIGINAL ARTICLE}

\section{REFERENCES:}

1. Quigley MA. Shifting burden of disease-epidemiological transition in India. Int J Epidemiol2006; 35: $1530-1$.

2. WHO (2014), Non-communicable Diseases by Country Profile, India.

3. Cardiovascular disease risk factors: New areas for research. WHO, Technical Report Series, no. 841, 1994. Available at: http://apps.who.int/iris/handle/10665/37644. (Last accessed on October $12^{\text {th }}, 2013$ ).

4. Bonita R. Surveillance of risk factors for the NCD's: The WHO STEPS approach, WHO: 2001.

5. Bonita R. WHO's response: An integrated approach to NCD Surveillance and prevention consultation on Stepwise Approach to Surveillance of NCD Risk Factors STEPS, STERO, WHO: 2002.

6. WHO. 2003. Diet, nutrition and the prevention of chronic diseases. Report of a Joint FAO/WHO Expert Consultation. WHO Technical Report Series No. 916. Geneva. WHO.

7. The Seventh Report of the Joint National Committee on Prevention, detection, Evaluation and treatment of high blood Pressure. Hypertension 2003; 42: 1206-52.

8. Vartika Saxena, SD Kandpal, Deepak Goel, Sushil Bansal. Prevalence of risk factors of NonCommunicable Diseases in rural population of Block Doiwala Dehradun. Indian Journal of Community Health 2011; 23 (2): 65-68.

9. Sochaliya KM, Parmar DV, Yadav SB. A Study on Prevalence of Life-Style Diseases and its Risk Factors in Urban Area of Jamnagar City. Natl J Community Med 2012; 3 (4): 595-600.

10. Acharyya T, Kaur P, Murhekar MV. Prevalence of behavioral risk factors, overweight and hypertension in the urban slums of North 24 Parganas District, West Bengal, India, 2010. Indian J Public Health 2014; 58: 195-8.

\section{AUTHORS:}

1. B. Nirmala Devi

2. M. Vijay Kumar

PARTICULARS OF CONTRIBUTORS:

1. Associate Professor, Department of Community Medicine, Osmania Medical College.

2. Senior Resident, Department of Community Medicine, Osmania Medical College.

FINANCIAL OR OTHER

COMPETING INTERESTS: None
NAME ADDRESS EMAIL ID OF THE CORRESPONDING AUTHOR:

Dr. B. Nirmala Devi, Associate Professor, Department of Community Medicine, Osmania Medical College, Koti, Hyderabad-500095.

E-mail: ndevirrt@yahoo.com

Date of Submission: 16/01/2015. Date of Peer Review: 17/01/2015. Date of Acceptance: 07/02/2015. Date of Publishing: 14/02/2015. 